\title{
Joint Pricing and Purchasing Decisions for the Dual-Channel Newsvendor Model with Partial Information
}

\author{
Jixiang Zhou, ${ }^{1}$ Yong Wang, ${ }^{1}$ and Xiaoming Yan $^{2}$ \\ ${ }^{1}$ School of Economics and Business Administration, Chongqing University, Chongqing 400044, China \\ ${ }^{2}$ School of Computer Science, Dongguan University of Technology, Dongguan, Guangdong 523808, China \\ Correspondence should be addressed to Yong Wang; wangyongkt@163.com
}

Received 19 March 2014; Revised 17 July 2014; Accepted 17 July 2014; Published 24 August 2014

Academic Editor: Guiomar Martín-Herrán

Copyright (c) 2014 Jixiang Zhou et al. This is an open access article distributed under the Creative Commons Attribution License, which permits unrestricted use, distribution, and reproduction in any medium, provided the original work is properly cited.

\begin{abstract}
We investigate a joint pricing and purchasing problem for the dual-channel newsvendor model with the assumption that only the mean and variance of the demand are known. The newsvendor in our model simultaneously distributes a single product through traditional retail and Internet. A robust optimization approach that maximizes the worst-case profit is adapted under the aforementioned conditions to model demand uncertainty and linear clearing functions that characterize the relationship between demand and prices. We obtain a close-form expression for the robust optimal policy. Illustrative simulations and numerical experiments show the effects of several parameters on the optimal policy and on newsvendor performance. Finally, we determine that the gap between newsvendor performance under demand certainty and uncertainty is minimal, which shows that the robust approach can significantly improve performance.
\end{abstract}

\section{Introduction}

A new entrepreneur who has recently launched a business on both traditional retail and Internet channels has had no time to collect historical data to estimate distribution information. However, she has a market forecast that provides her with several means and variances. This case has inspired the current study.

A number of industrial and government statistic reports show that Internet commerce is growing at a fast rate. In 2004, online retail sales comprised about $5.5 \%$ of all retail sales excluding those related to travel [1]. Many firms recognize the enormous potential of the Internet to reach customers, including Hewlett-Packard, Nike, Apple, Samsung, GOME, and Suning. These firms have begun to give additional attention to Internet sales channels. However, branded firms are not the only ones that distribute their products through the Internet; that is, small businesses are also taking advantage of this channel. In China, many small entrepreneurs sell products through both traditional (bricks-and-mortar) retail channel and the website Taobao, the biggest online shopping platform in Asia. On November 11, 2012, turnover in Taobao, including Taobao and Tianmao, reached 19.1 billion RMB. The number increased by $106.8 \%$ on the same day of the following year. However, how can small entrepreneurs make correct decisions that include pricing and ordering quantity to maximize profit when they face demand uncertainty with partial information?

According to Gallego and Moon [2], we can consider small entrepreneurs as newsvendors who purchase a single product and then distribute them through both the traditional retail channel and the Internet. In each channel, the newsvendor encounters a price-dependent, random demand. The newsvendor has partial information on the demand, for example, mean and variance. We can call this problem the distribution-free dual-channel newsvendor problem or the robust dual-channel newsvendor problem. Therefore, the present study is related to three areas: the robust newsvendor problem, pricing models and the newsvendor model, and dual-channel strategies.

Scarf [3] was the first to address the robust newsvendor problem. According to him, only the mean $\mu$ and variance $\sigma^{2}$ of the demand are known without any further assumption about the demand distribution form. Scarf provides a 
conservative approach, that is, the minimax approach, which aims to minimize the maximum cost resulting from the worst possible demand distribution. Gallego and Moon [2] provide evidence for Scarf's rule and extend his ideas to four cases, including recourse, fixed ordering cost, random yields, and multiproducts. Moon and Choi [4] extend the model of Gallego and Moon [2] and add the condition that customers may hesitate if the existing inventory is lower than a certain level. In a subsequent paper, Moon and Choi [5] use a similar approach to study a newsvendor problem with various degrees of product processing, such as raw materials, subassemblies, and finished products. These alternative policies are applied in made-to-order, made-in-advance, composite policy, and with/without budget limitation cases. Mostard et al. [6] find that the distribution-free order rule performs well in most realistic cases. Alfares and Elmorra [7] extend the results of Gallego and Moon [2] by incorporating a shortage penalty cost. Based on Alfares and Elmorra [7], Wu et al. [8] show that stockout cost significantly affects optimalordering decisions if a newsvendor is risk-averse. By contrast, Jammernegg and Kischka [9] study the cases of newsvendors who prefer risks. Liao et al. [10] extend the model of Moon and Choi [4] to include the penalty for failing to make a sale. Han et al. [11] derive an analogous closed-form order formula for the risk- and ambiguity-averse newsvendor problem to extend Scarf's formula. The maximum approach has also been applied to multiperiod or multiproduct inventory models. The works of Gallego [12], Moon and Gallego [13], Gallego [14], and Özler et al. [15] are examples of such literature.

However, some researchers believe that the aforementioned ideas are too conservative. Savage [16] provides a less conservative approach, that is, the minimax regret. Vairaktarakis [17], Yue et al. [18], Perakis and Roels [19], Lin and $\mathrm{Ng}$ [20], and Jiang et al. [21] have also investigated regret in the newsvendor model. Other researchers, such as Andersson et al. [22], turn entropy maximization into a goal. They compute the most likely demand distribution in the maximum entropy sense.

All the aforementioned studies assume that pricing is an exogenous decision, ordering quantity is the only decision variable, and the newsvendor sells products through only one channel. In reality, however, pricing is also a useful and essential element in managing a company. An appropriate pricing strategy can increase company profit. Moreover, with the development of the Internet, the newsvendor can choose this technology as a second distribution channel. In the current study, we develop a joint decision strategy that includes pricing and purchasing quantity to maximize the expected profit of the newsvendor who is distributing products through both the traditional retail channel and the Internet.

The original newsvendor problem initially assumes that price is an exogenous decision. For a newsvendor, however, pricing is also a useful and essential element in operations. Whitin [23] was the first to incorporate pricing decision into the newsvendor problem and to investigate the optimization problem of simultaneously determining inventory and selling price under demand uncertainty. Petruzzi and Dada [24] provide meaningful extensions of the newsvendor-pricing problem and analyze the effect of the nature of the stochastic demand function on pricing and stocking decisions. Khouja [25] and Petruzzi and Dada [26] further analyze joint determination of inventory and pricing decisions for the newsvendor problem under a two-period retail setting. Based on these studies, Pan et al. [27] present a model that produces joint pricing and ordering decision for a dominant retailer with demand uncertainty under a declining price environment. Meanwhile, Yang [28] evaluates an optimal replenishment and pricing policy for a price-sensitive demand. Karakul [29] studies joint pricing and procurement of fashion products in clearance markets. Chen and Bell [30] address simultaneous determination of price and inventory replenishment when customers return products to the newsvendor. He et al. [31] extend the newsvendor problem to include an uncertain demand that is sensitive to both price and effort of the newsvendor.

Studies, such as those Chen et al. [32] and Xing et al. [33], have also addressed combined pricing and ordering decision under different degrees of risk tolerance. Some researchers, such as Hua et al. [34], Serel [35], and Li et al. [36], have also investigated this problem under different conditions.

All the aforementioned studies assume that demand is deterministic or demand distribution is known. Moreover, they only consider newsvendors distributing products through the traditional retail channel. However, obtaining demand distribution under rapidly changing market conditions is difficult. A newsvendor may also have insufficient time to collect historical data for estimating distribution information. In the current study, we consider that the newsvendor distributes products through both the traditional retail channel and the Internet and develop a joint decision strategy for pricing and ordering while the newsvendor only possesses partial demand information.

In the past several years, research on the dual-channel problem has gained considerable attention among marketing and supply chain managers. Balasubramanian [37] studies the different factors that affect consumer choice and channel use. Levary and Mathieu [38] predict that hybrid stores will earn maximum profits in the future. Chiang et al. [39] proposes that adding a direct channel can decrease profit loss of the manufacturer. Yao and Liu [40] study customer diffusion between an e-tail channel and a retail channel. The results of this study reflect that demands on both channels are stable under certain conditions. With regard to prices, Fruchter and Tapiero [41] find that a manufacturer charges the same price in both channels. In addition, Cai et al. [42] illustrate that a consistent pricing scheme can reduce channel conflict by inducing additional profit for the retailer. Xu et al. [43] extend the result of Chiang et al. [39] by examining the effects of price and delivery lead-time decisions on the channel configuration strategy under the manufacturer-owned mode. Hua et al. [44] investigate the influence of lead time on decisions. Similarly, Dan et al. [45] examine the effects of services on supply chain performance and decisions. Chen and Bell [46] also investigate how a firm that experiences customer returns can enhance profit by using different customer return policies, such as full refund and no return, as a mechanism to segment the market into a dual-channel structure. Studies on pricing strategies under asymmetric information include 
those of Yao et al. [47], Yue and Liu [48], Yan and Ghose [49], and Yan and Pei [50]. All the aforementioned studies consider demand as deterministic. By contrast, Huang et al. [51] assume that the absolute value of the difference between actual demand and the original plan is deterministic. In the present study, we assume that demand is random and only partial demand information is known. This hypothesis is necessary to make correct decisions because of rapid changes in the market.

We generalize the maximin approach to joint pricing and purchasing quantity decisions in the dual-channel newsvendor model with partial demand information, in which the newsvendor distributes a single product through both traditional (bricks-and-mortar) retail and Internet channels. We aim to provide a decision-making aid to the newsvendor and analyze the effects of uncertainty on the pricing and purchasing decisions as well as on the performance of the newsvendor. The contributions of this study are as follows.

(1) A dual-channel newsvendor model with robust joint pricing and purchasing decisions for depicting individual small business.

(2) A close-form expression for an optimal pricing and purchasing policy under a worst-case scenario. Optimal strategies can be easily analyzed when explicit solutions are available.

(3) A small gap between the performance of the newsvendor under demand certainty and uncertainty, which shows that the robust approach applied in our problem is less conservative than available strategies.

The remainder of this paper is organized as follows. In Section 2, we introduce the notations and discuss the joint pricing and purchasing decision in a robust dual-channel newsvendor model. We then formulate the robust optimal pricing and purchasing policies. In Section 3, we present the numerical results and analyze parameter sensitivity. We conclude the results and suggest topics for future research in Section 4 .

\section{The Model}

A newsvendor is assumed to purchase a single product with a quantity of $q$ at a unit cost of $c$ and distributes it through the traditional retail channel at a price of $p_{r}$ and through the Internet at a price of $p_{i}$. For simplicity, the unit sales cost is zero. In each channel, the newsvendor faces a random pricedependent demand for the product observed during the sales period and possesses only partial information on demand. Moreover, the randomness of the demand is independent of price. The newsvendor satisfies the demand as much as possible with the preordered unit. We assume that the unit salvage value for leftover and the unit penalty cost when the product cannot satisfy the demand are both zero. Based on Choi [52], Raju and Roy [53], Chiang et al. [39], Yue and Liu [48], Huang and Swaminathan [54], Hua et al. [44], Huang et al. [51], and Dan et al. [45], the corresponding demand functions in the two channels can be formulated as follows:

$$
\begin{aligned}
& D_{i}=\rho D-\alpha_{1} p_{i}+\beta_{1} p_{r}, \\
& D_{r}=(1-\rho) D-\alpha_{2} p_{r}+\beta_{2} p_{i} .
\end{aligned}
$$

To avoid trivial problems, it is necessary to impose additional inequality constraints on the parameters in order to guarantee that: (1) $c<p_{r}, p_{i}$; (2) $D_{r}, D_{i}>0$. Then, the total demand faced by the newsvendor in the two channels can be determined by the following formula:

$$
D_{\mathrm{sc}}=D-\left(\alpha_{1}-\beta_{2}\right) p_{i}-\left(\alpha_{2}-\beta_{1}\right) p_{r} .
$$

In the preceding formulas, subscripts $r$ and $i$ denote the traditional retail channel and the Internet channel, respectively. Equations (1) and (2) indicate that the demand in the Internet channel $D_{i}$ and that in the traditional retail channel $D_{r}$, respectively, both depend on the prices $p_{r}$ and $p_{i}$. $D$, a random variable, denotes the predicted total potential demand in the two channels if the product is free. When information is incomplete, we can simply obtain the mean $\mu$, variance $\sigma^{2}$, and nonnegative support information of the total potential demand. When the prices $p_{i}$ and $p_{r}$ are zero, the share of the demand that goes to the Internet channel is $\rho$, whereas the rest, that is, $1-\rho$, goes to the traditional retail channel. This result can be interpreted as the loyalty or preference of customers for the Internet channel. A large $\rho$ indicates that customers purchase more from the Internet than from the traditional channel. $\alpha_{1}$ and $\alpha_{2}$ are the coefficients of the selfprice elasticity of $D_{i}$ and $D_{r}$, respectively. $\beta_{1}$ and $\beta_{2}$, which are cross-price sensitivities, reflect the degrees to which products sold via the two channels can be regarded as substitutes. Based on Huang et al. [55], we assume that $\alpha_{i}>\beta_{i}>0$ for $i=1,2$, which reflects that the effect of self price on elasticity is more dominant that of cross price. Following Yue and Liu [48] and Huang et al. [51], we assume that the effects of cross price are symmetric to maintain analytical tractability, that is, $\beta_{1}=\beta_{2}=\beta$.

We assume that prior to the sales season, the newsvendor must make a joint decision regarding ordering quantity $q$ and selling prices $p_{i}$ and $p_{r}$ to maximize the expected profit. For simplicity, we also assume that the product must satisfy the traditional retail channel first and that ordering quantity $q$ can always satisfy the need of the traditional retail channel; that is, $q-D_{r} \geq 0$ is always set up. Using the preceding notations and assumptions, the newsvendor profit can be described as follows:

$$
\pi\left(q, p_{i}, p_{r}\right)=p_{r} D_{r}+p_{i} \min \left\{\left(q-D_{r}\right), D_{i}\right\}-c q .
$$

A robust newsvendor will seek a conservative pricing and purchasing decision to maximize the worst-case profit because partial information of the total potential demand is known. Thus, the objective of the newsvendor can be rewritten as follows:

$$
\max _{p_{i}, p_{r}, q} \inf _{D \sim\left(\mu, \sigma^{2}\right)} E\left[\pi\left(p_{i}, p_{r}, q\right)\right] .
$$


Since $\min \left\{\left(q-D_{r}\right), D_{i}\right\}=D_{i}-\left(D_{i}-\left(q-D_{r}\right)\right)^{+}$, we obtain that

$$
\begin{aligned}
E\left[\pi\left(p_{i}, p_{r}, q\right)\right]= & p_{r} E\left(D_{r}\right)+p_{i} E\left(D_{i}\right) \\
& -p_{i} E\left[\left(D_{i}-\left(q-D_{r}\right)\right)^{+}\right]-c q .
\end{aligned}
$$

Along the lines of Petruzzi and Dada [24], we define $z=\left(\alpha_{1}-\right.$ $\beta) p_{i}+\left(\alpha_{2}-\beta\right) p_{r}+q-\mu, \Lambda(z)=\left(\sqrt{\sigma^{2}+z^{2}}+z\right) / 2, \Theta(z)=$ $\Lambda(z)-z=\left(\sqrt{\sigma^{2}+z^{2}}-z\right) / 2$, and then $q=z-\left(\alpha_{1}-\beta\right) p_{i}-\left(\alpha_{2}-\right.$ $\beta) p_{r}+\mu$. With these variable transformations and following Gallego and Moon [2], we get

$$
\begin{aligned}
f\left(p_{i}, p_{r}, z\right) & =\inf _{D \sim\left(\mu, \sigma^{2}\right)} E\left[\pi\left(p_{i}, p_{r}, q\right)\right] \\
& =\Psi\left(p_{i}, p_{r}\right)-L\left(p_{i}, z\right),
\end{aligned}
$$

where

$$
\begin{aligned}
& \Psi\left(p_{i}, p_{r}\right)= p_{r}\left[(1-\rho) \mu-\alpha_{2} p_{r}+\beta p_{i}\right] \\
&+p_{i}\left(\rho \mu-\alpha_{1} p_{i}+\beta p_{r}\right) \\
&+c\left[\left(\alpha_{1}-\beta\right) p_{i}+\left(\alpha_{2}-\beta\right) p_{r}-\mu\right], \\
& L\left(p_{i}, z\right)=\left(p_{i}-c\right) \Theta(z)+c \Lambda(z) .
\end{aligned}
$$

Equation (8) indicates the riskless profit function, for example, Mills [56] and Petruzzi and Dada [24]. The function indicates the profit for the given prices under a certainty equivalent problem and $D$ is replaced with $\mu$. Equation (9) indicates the loss function [57] because of the uncertainty of the total potential demand. Thus, from (7), we can assume that (1) the expected profit with uncertainty is less than that with certainty and (2) we can increase the expected profit by decreasing the uncertainty. Therefore, the objective is transformed into

$$
\max _{p_{i}, p_{r}, z} f\left(p_{i}, p_{r}, z\right) .
$$

The corresponding optimal purchasing quantity and pricing policy is to purchase $q^{*}=z^{*}-\left(\alpha_{1}-\beta\right) p_{i}^{*}-\left(\alpha_{2}-\beta\right) p_{r}^{*}+\mu$ units to sell at the traditional retail price of $p_{r}^{*}$ and the Internet price of $p_{i}^{*}$, where $z^{*}, p_{r}^{*}$, and $p_{i}^{*}$ maximize the expected profit in the worst-case scenario $f\left(p_{i}, p_{r}, z\right)$. In order to maximize $f\left(p_{i}, p_{r}, z\right)$. We obtain the first and second partial derivatives of $f\left(p_{i}, p_{r}, z\right)$ with respect to $p_{r}, p_{i}$, and $z$ to maximize $f\left(p_{i}\right.$, $\left.p_{r}, z\right)$, as follows:

$$
\begin{gathered}
\frac{\partial f\left(p_{r}, p_{i}, z\right)}{\partial p_{r}}=-2 \alpha_{2} p_{r}+2 \beta p_{i}+2\left(\alpha_{2}-\beta\right) c \\
+(1-\rho) \mu, \\
\frac{\partial^{2} f\left(p_{r}, p_{i}, z\right)}{\partial p_{r}^{2}}=-2 \alpha_{2}, \\
\frac{\partial f\left(p_{r}, p_{i}, z\right)}{\partial p_{i}}=-2 \alpha_{1} p_{i}+2 \beta p_{r}+2\left(\alpha_{1}-\beta\right) c+\rho \mu-\Theta(z),
\end{gathered}
$$

$$
\begin{gathered}
\frac{\partial^{2} f\left(p_{r}, p_{i}, z\right)}{\partial p_{i}^{2}}=-2 \alpha_{1}, \\
\frac{\partial^{2} f\left(p_{r}, p_{i}, z\right)}{p_{r} p_{i}}=2 \beta, \\
\frac{\partial f\left(p_{r}, p_{i}, z\right)}{\partial z}=\left(p_{i}-c\right) \frac{\Theta(z)}{\sqrt{\sigma^{2}+z^{2}}}-c \frac{\Lambda(z)}{\sqrt{\sigma^{2}+z^{2}}}, \\
\frac{\partial^{2} f\left(p_{r}, p_{i}, z\right)}{\partial z^{2}}=-p_{i} \frac{\sigma^{2}}{\left(\sigma^{2}+z^{2}\right)^{3 / 2}} .
\end{gathered}
$$

Equation (17) shows that $f\left(p_{r}, p_{i}, z\right)$ is concave in $z$ for the given prices of $p_{r}$ and $p_{i}$. Thus, $z$ can be regarded as a function of $p_{r}$ and $p_{i}$. The original problem can then be reduced to an optimization problem over the single variable $z$, and the result is substituted into $f\left(p_{r}, p_{i}, z\right)$. Whitin [23] was the first to use this method. Similarly, from (12), (14), and (15), we find that $f\left(p_{r}, p_{i}, z\right)$ is jointly concave in $p_{r}$ and $p_{i}$ for a given $z$. Therefore, we follow the method of Zabel [58] and Petruzzi and Dada [24] and first obtain the optimal value of $p_{r}$ and $p_{i}$ as a function of $z$, and then search for the optimal $z$ to maximize $f\left(p_{r}^{*}, p_{i}^{*}, z\right)$. We can obtain the same conclusions from two methods, but only the latter approach is described in this paper.

From (11) and (13), we obtain the following.

Lemma 1. For a fixed $z$, the optimal traditional retail price and Internet price are determined uniquely as a function of $z$, as follows:

$$
\begin{aligned}
& p_{i}^{*}=p_{i 1}-\frac{\alpha_{2}}{2\left(\alpha_{1} \alpha_{2}-\beta^{2}\right)} \Theta(z), \\
& p_{r}^{*}=p_{r 1}-\frac{\beta}{2\left(\alpha_{1} \alpha_{2}-\beta^{2}\right)} \Theta(z),
\end{aligned}
$$

where $p_{i 1}=\left(\left[\left(\alpha_{2}-\beta\right) \rho+\beta\right] \mu+\left(\alpha_{1} \alpha_{2}-\beta^{2}\right) c\right) / 2\left(\alpha_{1} \alpha_{2}-\beta^{2}\right)$, $p_{r 1}=\left(\left[\alpha_{1}-\left(\alpha_{1}-\beta\right) \rho\right] \mu+\left(\alpha_{1} \alpha_{2}-\beta^{2}\right) c\right) / 2\left(\alpha_{1} \alpha_{2}-\beta^{2}\right)$, respectively, denote the optimal riskless Internet and traditional retail prices, which maximize $\Psi\left(p_{i}, p_{r}\right)$. These optimal prices have the same form as those in Huang et al. [51]. Based on (18), for any given $z$, the optimal Internet price will increase and the optimal traditional retail price will decrease with increasing $\rho$. These results are reasonable because if the base level of the demand in one channel is larger than that in the other channel, then the price in the former should be set higher than that in the latter. Given that $\beta, \alpha_{1} \alpha_{2}-\beta^{2}$, and $\Theta(z)$ are positive, $p_{i}^{*}<p_{i 1}$ and $p_{r}^{*}<p_{r 1}$; that is, customers purchasing from both traditional retail and Internet channels can benefit from the demand uncertainty. Substituting (18) into (10), the optimization problem becomes a maximization problem over the single variable $z$, as follows:

$$
\max _{z} f\left(p_{i}(z), p_{r}(z), z\right) .
$$

Therefore, the effort required to compute for the optimal purchasing quantity and pricing policy depends on the shape of $f\left(p_{i}(z), p_{r}(z), z\right)$. However, as demonstrated in Theorem 2, 
$f\left(p_{i}(z), p_{r}(z), z\right)$ may have multiple points that satisfy the first-order optimality condition depending on the parameters of the problem.

Theorem 2. The optimal purchasing quantity and pricing policy are to purchase $q^{*}=z^{*}-\left(\alpha_{1}-\beta\right) p_{i}^{*}-\left(\alpha_{2}-\beta\right) p_{r}^{*}+\mu$ units to sell at the traditional retail price of $p_{r}^{*}$ and the Internet price of $p_{i}^{*}$, where $p_{r}^{*}$ and $p_{i}^{*}$ are specified by Lemma 1 , and $z^{*}$ is determined according to the following:

(a) If $4\left(p_{i 1}-2 c\right)\left(\alpha_{1} \alpha_{2}-\beta^{2}\right)-\alpha_{2} \sigma \leq 0$, then $z^{*}$ is the largest $z$ in region $[0,+\infty)$ that satisfies $d f\left(p_{i}(z)\right.$, $\left.p_{r}(z), z\right) / d z=0$.

(b) If $4\left(p_{i 1}-2 c\right)\left(\alpha_{1} \alpha_{2}-\beta^{2}\right)-\alpha_{2} \sigma>0$, then $z^{*}$ is the unique $z$ in region $[0,+\infty)$ that satisfies $d f\left(p_{i}(z)\right.$, $\left.p_{r}(z), z\right) / d z=0$.

Proof. From the chain rule and Lemma 1:

$$
\begin{aligned}
& \frac{d f\left(p_{i}(z), p_{r}(z), z\right)}{d z} \\
& \quad=\left(p_{i 1}-\frac{\alpha_{2}}{2\left(\alpha_{1} \alpha_{2}-\beta^{2}\right)} \Theta(z)\right) \frac{\Theta(z)}{\sqrt{\sigma^{2}+z^{2}}}-c .
\end{aligned}
$$

To identify the values of $z$ that satisfy the first-order optimization condition, let $R(z) \equiv d f\left(p_{i}(z), p_{r}(z), z\right) / d z$ and consider finding the zeros of $R(z)$ :

$$
\begin{aligned}
& \frac{d R(z)}{d z} \\
& =-\frac{\Theta(z)}{\sigma^{2}+z^{2}}\left[\left(1+\frac{z}{\sqrt{\sigma^{2}+z^{2}}}\right)\left(p_{i 1}-\frac{\alpha_{2}}{2\left(\alpha_{1} \alpha_{2}-\beta^{2}\right)} \Theta(z)\right)\right. \\
& \left.-\frac{\alpha_{2}}{2\left(\alpha_{1} \alpha_{2}-\beta^{2}\right)} \Theta(z)\right] \text {, } \\
& \frac{d^{2} R(z)}{d z^{2}} \\
& =\frac{d R(z) / d z}{-\Theta(z) /\left(\sigma^{2}+z^{2}\right)}\left[-\frac{\Theta(z)}{\sigma^{2}+z^{2}}\right]^{\prime} \\
& -\frac{\Theta(z)}{\sigma^{2}+z^{2}}\left[\frac{p_{i 1} \sigma^{2}}{\left(\sigma^{2}+z^{2}\right)^{3 / 2}}+\frac{\alpha_{2} z^{2} \Theta(z)}{2\left(\alpha_{1} \alpha_{2}-\beta^{2}\right)\left(\sigma^{2}+z^{2}\right)^{3 / 2}}\right. \\
& \left.+\frac{\alpha_{2} \sigma^{2}}{4\left(\alpha_{1} \alpha_{2}-\beta^{2}\right)\left(\sigma^{2}+z^{2}\right)}\right] \text {. }
\end{aligned}
$$

All $z$ in region $[0,+\infty)$ satisfies the condition $p_{i 1} \sigma^{2} /\left(\sigma^{2}+\right.$ $\left.z^{2}\right)^{3 / 2}+\alpha_{2} z^{2} \Theta(z) / 2\left(\alpha_{1} \alpha_{2}-\beta^{2}\right)\left(\sigma^{2}+z^{2}\right)^{3 / 2}+\alpha_{2} \sigma^{2} / 4\left(\alpha_{1} \alpha_{2}-\right.$ $\left.\beta^{2}\right)\left(\sigma^{2}+z^{2}\right)>0$; therefore,

$$
\left.\frac{d^{2} R(z)}{d z^{2}}\right|_{d R(z) / d z=0}<0
$$

This equation indicates that $R(z)$ is either a monotone or a unimodal, which implies that $R(z)=d f\left(p_{i}(z), p_{r}(z), z\right) / d z$ has two roots at most. Furthermore, $R(+\infty)=-c<0$. If the equation has two roots, then the sign for $R(z)$ is changed from negative to positive and again from positive to negative. Thus, the larger root corresponds to a local maximum, whereas the smaller one corresponds to a local minimum of $f\left(p_{i}(z), p_{r}(z), z\right) . R(0) \leq 0$ is a sufficient condition that indicates that $R(z)$ has two roots because $8\left(\alpha_{1} \alpha_{2}-\beta^{2}\right)>0$. The sufficient condition is equivalent to $8\left(\alpha_{1} \alpha_{2}-\beta^{2}\right) R(0) \leq 0$, that is,

$$
\begin{aligned}
8\left(\alpha_{1} \alpha_{2}-\beta^{2}\right) R(0) & =4\left(p_{i 1}-2 c\right)\left(\alpha_{1} \alpha_{2}-\beta^{2}\right)-\alpha_{2} \sigma \\
& \leq 0 .
\end{aligned}
$$

An $R(z)$ with only one root denotes a change in the sign of $R(z)$ from positive to negative, which is a sufficient condition for the unimodality of $R(z)$ is $R(0)>0$. The proof of $(\mathrm{c})$ is similar to that of (b) and is, therefore, omitted.

\section{Numerical Simulation}

Based on the previous analysis, we illustrate our robust joint pricing and purchasing quantity optimization model through several numerical examples to provide several key managerial insights by answering the following questions. What is the impact of $\rho$ on the optimal Internet price and traditional retail price? How big is the gap between the profits under demand certainty and uncertainty with various values of $\rho$ ? What are the effects of some key parameters, such as $\mu$, $\sigma, \alpha_{1}, \alpha_{2}$, and $\beta$, on the robust solutions and the profits under demand certainty and uncertainty? Based on previous numerical studies, for example, Yue and Liu [48], we use the following parameter values: $\mu=250, \sigma=25, \alpha_{1}=\alpha_{2}=1$, $\beta=0.5, \rho=0.5$, and $c=10$.

3.1. Effect of Varying the Demand Share That Goes to the Internet Channel $(\rho)$. The dual channel is reduced to a single traditional retail channel or Internet channel when $\rho=0$ or $\rho=1$. The effects of demand share goes to the Internet channel for the optimal Internet price. The traditional retail price and the profits under various scenarios are shown in Figures 1 and 2.

Figure 1 shows that as $\rho$ increases, the newsvendor must raise Internet price and reduce traditional retail price; meanwhile, if $\rho$ decreases, then the newsvendor must take the opposite action. These actions are reasonable because if consumers prefer purchasing through the Internet channel, then the newsvendor has sufficient market power to increase Internet price. Figure 2 shows that the newsvendor will achieve profit maximization if all customers prefer buying through a single channel. Meanwhile, the newsvendor obtains minimum profit when $\rho=0.5$; that is, the customers are equally divided in channel preference. The major criticism of the maximin approach is that the resulting policies can be too conservative. However, Figure 2 indicates that if the newsvendor sets the optimal prices and purchasing quantity by using the robust model, then the profit earned by the newsvendor under demand uncertainty is slightly lower than that under demand certainty. In fact, the profit of the 


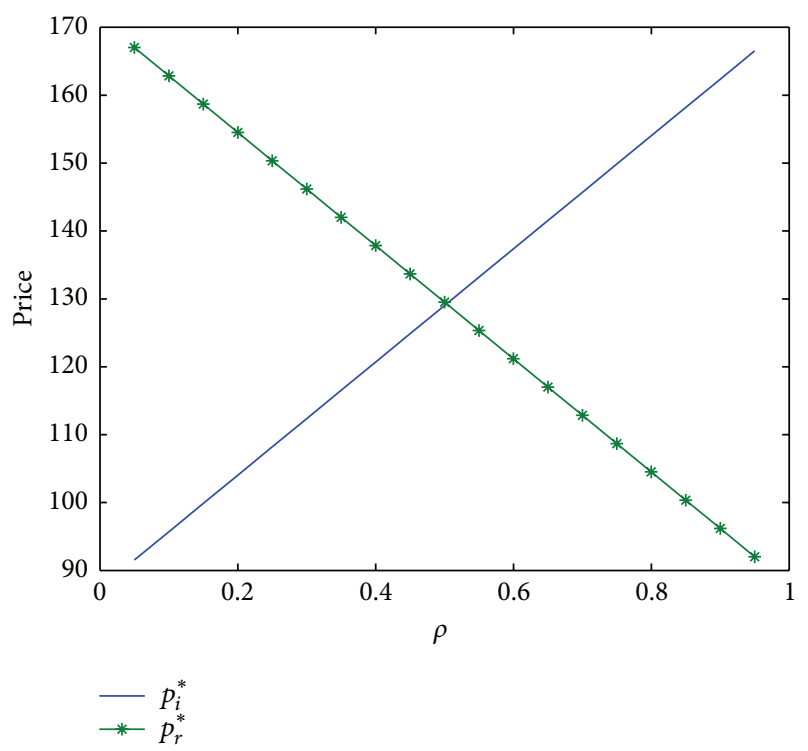

FIGURE 1: Impact of $\rho$ on the optimal internet price and traditional retail price.

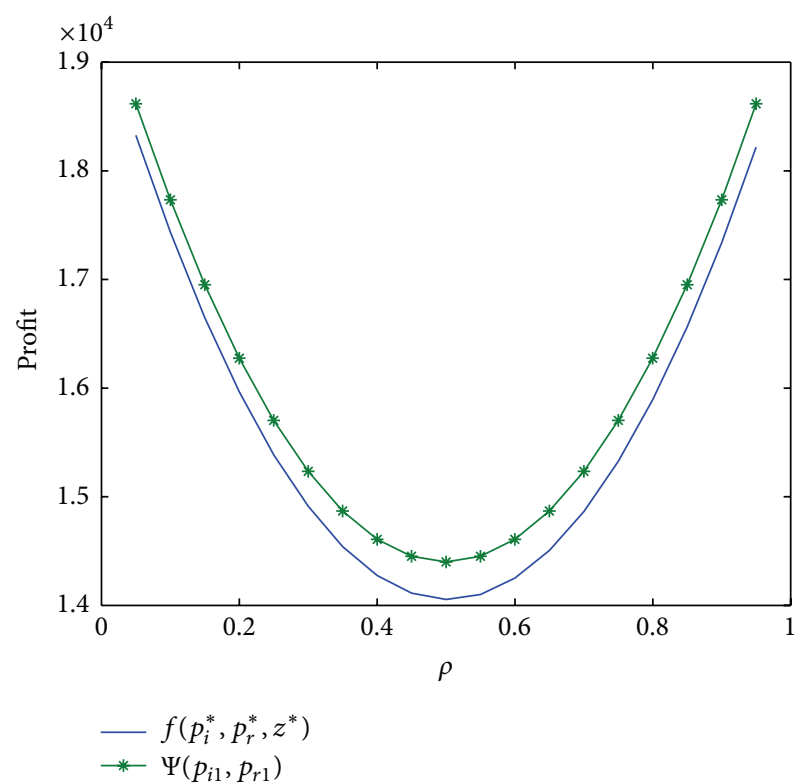

FIGURE 2: Impact of $\rho$ on the profits under demand certainty and uncertainty.

newsvendor under demand uncertainty is more than $97.5 \%$ of that under demand certainty. Determining whether the robust joint decision model will remain less conservative when they face additional variables is an interesting topic for future study.

3.2. Sensitivity Analysis of Parameters. We also designed experiments to analyze the effects of some key parameters on the robust solutions. Let $Q$ denote the optimal purchasing quantity when demand is certain, that is, the total demand faced by the newsvendor under demand certainty. Let $f^{*}=$ $f\left(p_{i}^{*}, p_{r}^{*}, q^{*}\right)$ and $\Psi^{*}=\Psi\left(p_{i 1}, p_{r 1}\right)$, respectively, denote

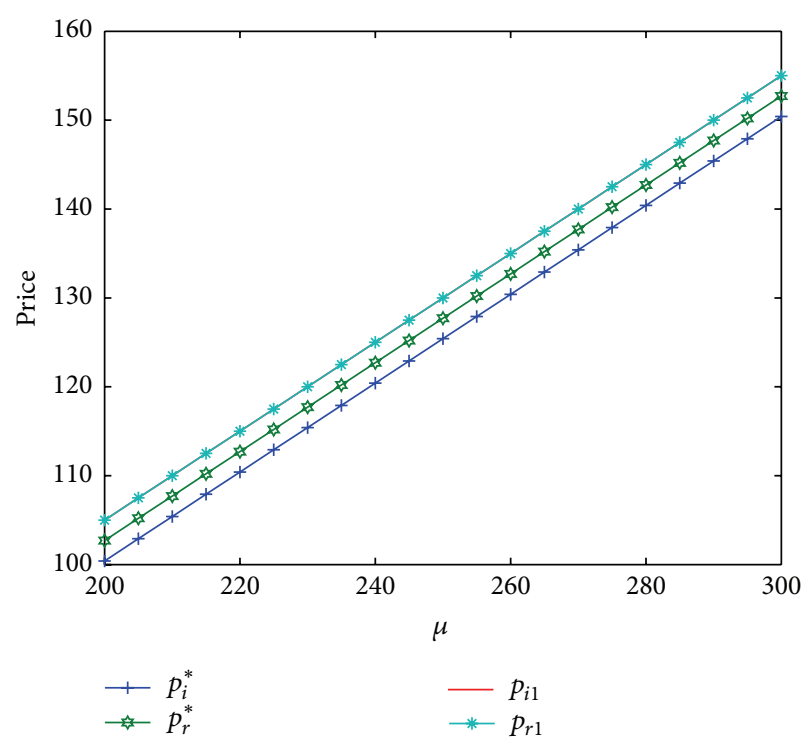

FIGURE 3: Impact of $\mu$ on pricings under demand certainty and uncertainty.

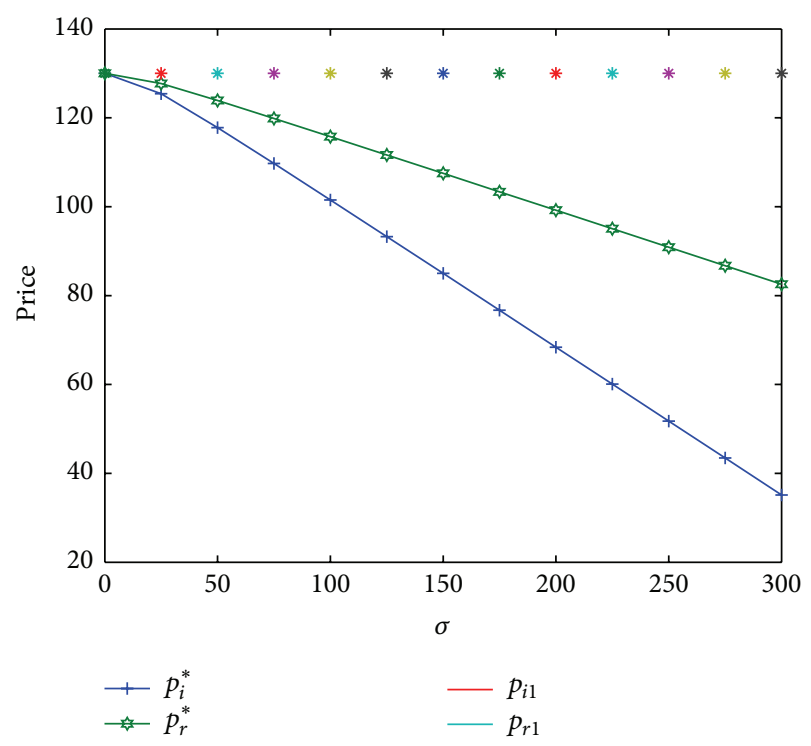

FIGURE 4: Impact of $\sigma$ on pricings under demand certainty and uncertainty.

maximum profit under demand uncertainty and certainty. The results of our experiments are shown in Figures 3, 4, 5, $6,7,8,9,10,11,12,13,14,15,16$, and 17 .

As shown in Figures 3 to 7 , the results of the experiments are consistent with the theory analyzed in the previous section. The optimal riskless Internet price of $p_{i 1}$ is never less than the robust optimal Internet price of $p_{i}^{*}$. The same situation is true for the optimal riskless traditional retail price of $p_{r 1}$. As shown in Figure 3, as $\mu$ increases, the newsvendor must increase both Internet and traditional retail prices as $\mu$ increases. This action can be considered an intuitive response because increasing the expected demand will lead to soaring 


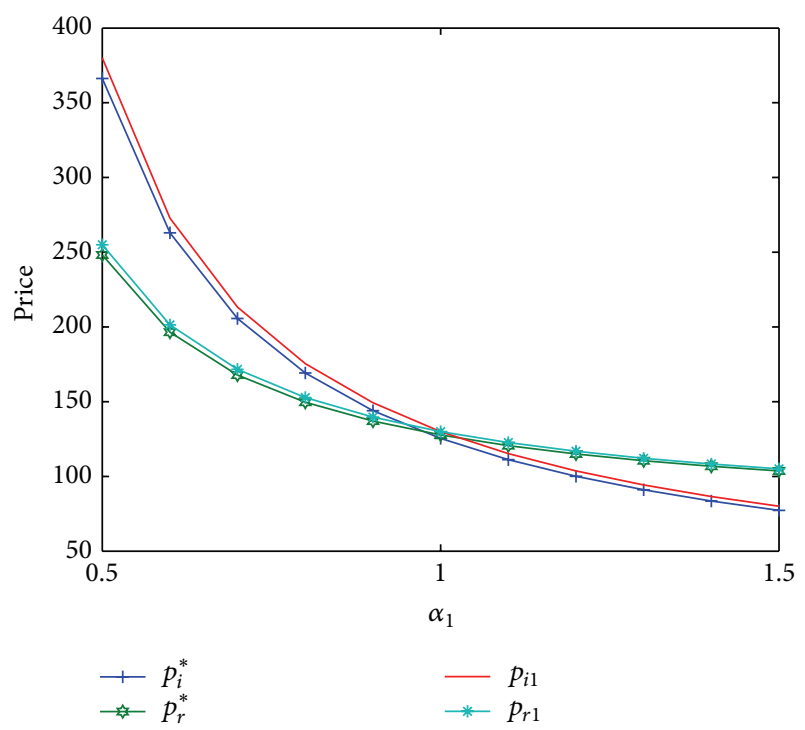

Figure 5: Impact of $\alpha_{1}$ on pricings under demand certainty and uncertainty.

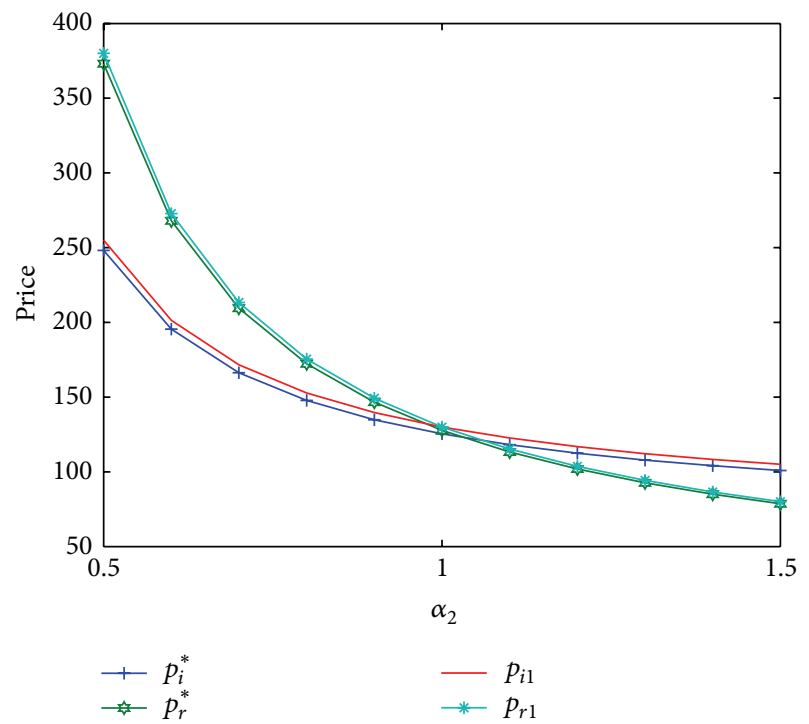

FIGURE 6: Impact of $\alpha_{2}$ on pricings under demand certainty and uncertainty.

prices. However, increasing $\sigma$ will produce the opposite effect (Figure 4). Moreover, the optimal prices decline more slowly when $\sigma \leq 25$ than when $\sigma>25$. Meanwhile, the optimal Internet price declines faster than the optimal traditional retail price as $\sigma$ decreases. Furthermore, by calculation, we find that the effect of $\sigma$ on the optimal prices is more less than that of $\mu$. Figures 5 and 6 show that the optimal prices decrease as $\alpha_{1}\left(\alpha_{2}\right)$ increases. Furthermore, when $\alpha_{1} \leq \alpha_{2}$, we find that $p_{i}^{*} \geq p_{r}^{*}$ and $p_{i 1} \geq p_{r 1}$; and when $\alpha_{1}>\alpha_{2}$, we find that $p_{i}^{*}<p_{r}^{*}$ and $p_{i 1}<p_{r 1}$. That is, when the customers are less sensitive to the price of a certain channel, the channel price will be higher. From Figure 7, we can see that prices increase faster as $\beta$ increases. Prices increase even

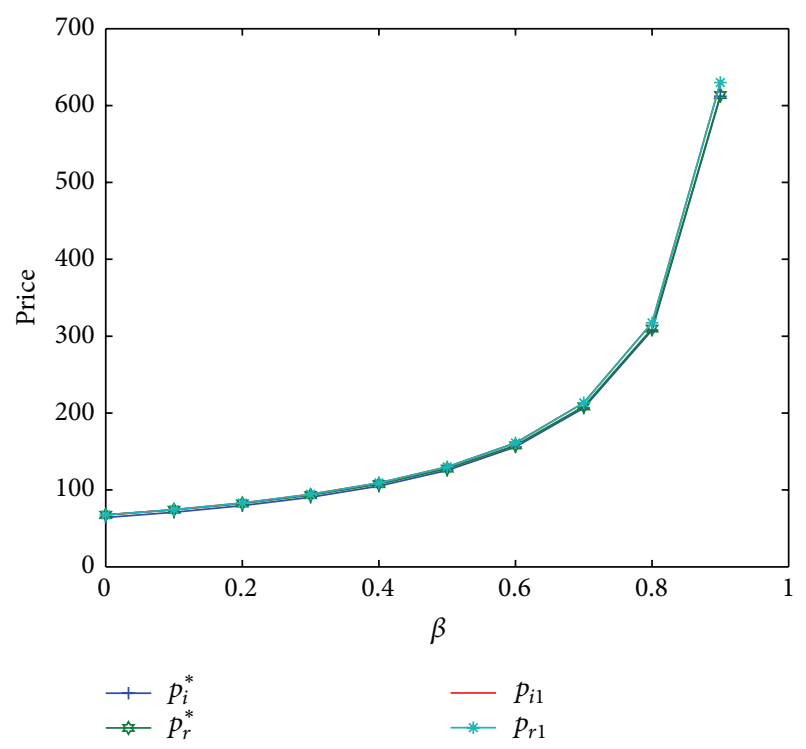

Figure 7: Impact of $\beta$ on pricings under demand certainty and uncertainty.

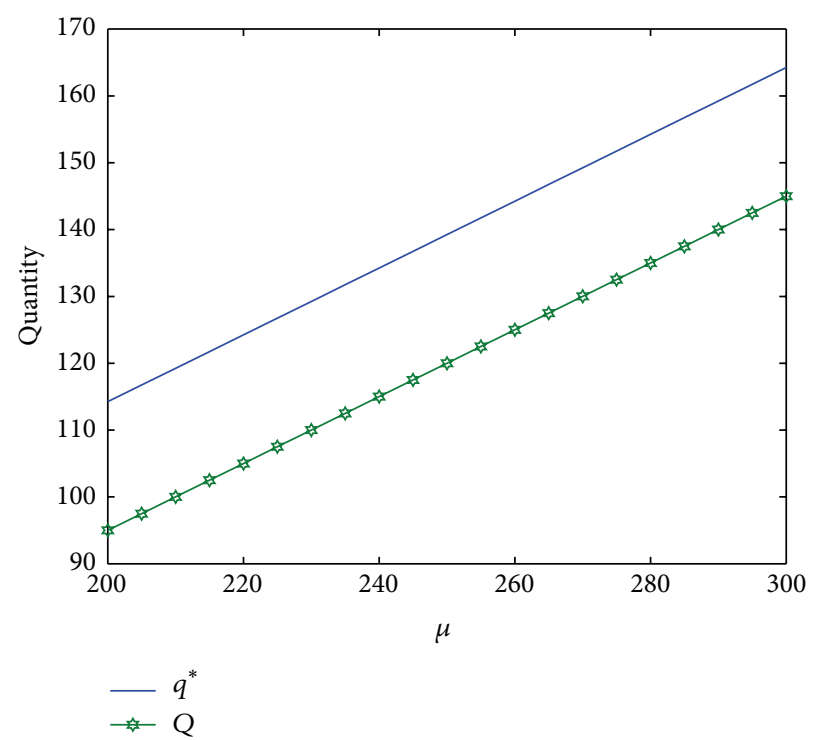

FIGURE 8: Impact of $\mu$ on ordering quantity under demand certainty and uncertainty.

more rapidly when $\beta \geq 0.5$. This result indicates that the change in cross-price sensitivity has a more important role in price changes when the gap between the self-price elasticity coefficient and cross-price sensitivity decreases.

Figure 8 shows that the newsvendor must increase ordering quantity as $\mu$ increases. This action can be considered as an intuitive response because increasing the expected demand will force the newsvendor to purchase additional products to sell. Figure 9 indicates that the optimal ordering quantity of the newsvendor under demand uncertainty increases with increasing $\sigma$. By contrast, $\sigma$ does not affect ordering quantity under demand certainty. This result is 


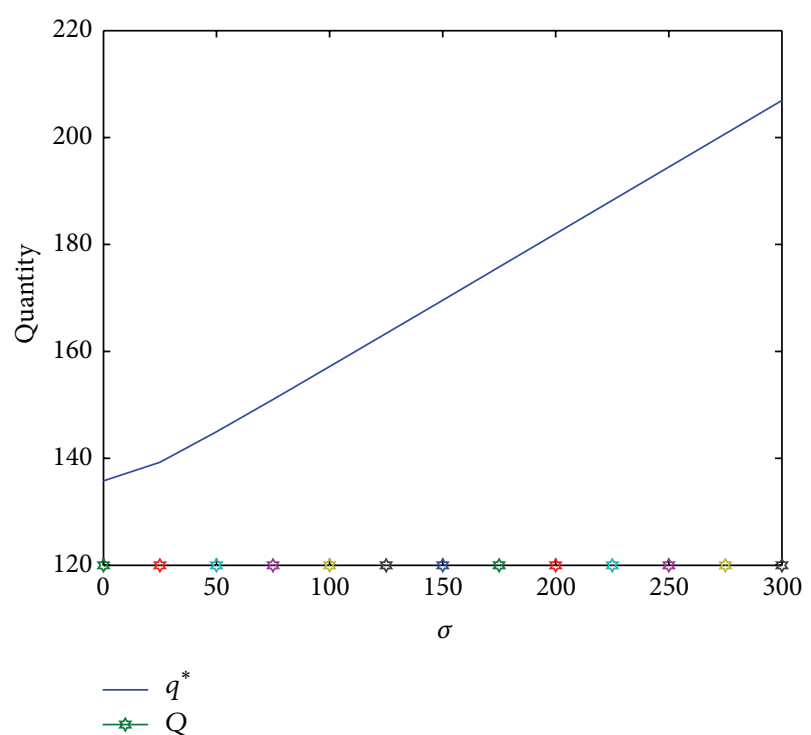

FIGURE 9: Impact of $\sigma$ on ordering quantity under demand certainty and uncertainty.

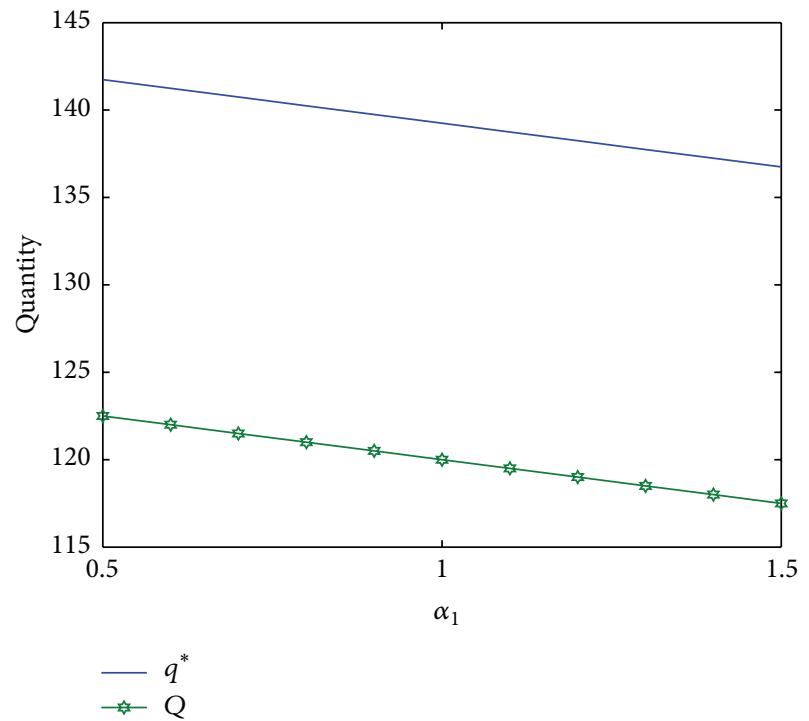

FIGURE 10: Impact of $\alpha_{1}$ on ordering quantity under demand certainty and uncertainty.

straightforward because an increase in $\sigma$ indicates an increase in risk, and the newsvendor must purchase additional products to respond to risk. Moreover, the optimal ordering quantity under demand uncertainty increases more slowly when $\sigma \leq 25$ than when $\sigma>25$. We also find that the relative increase in ordering quantity is considerably smaller when $\sigma$ increases significantly, which indicates that our robust model exhibits good stability. From Figures 10 to 11, we can see that ordering quantities decrease as $\alpha_{1}$ or $\alpha_{2}$ increases. Moreover, $\alpha_{1}$ and $\alpha_{2}$ have the same effect on ordering quantities. Figure 12 shows that ordering quantities increase with increasing $\beta$, which is consistent with (1) and (2). These equations indicate that an increasing $\beta$ increases the demand

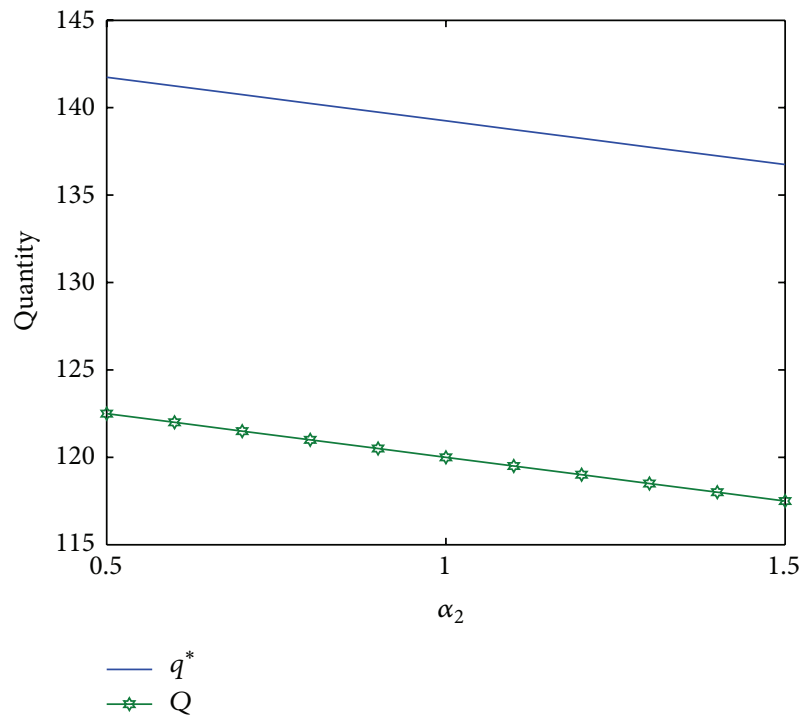

FIGURE 11: Impact of $\alpha_{2}$ on ordering quantity under demand certainty and uncertainty.

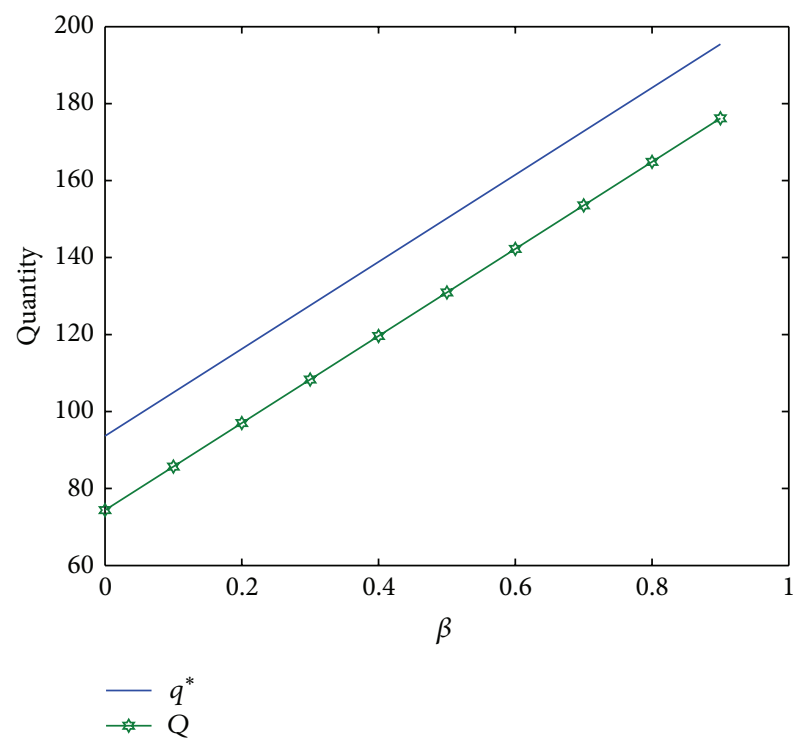

FIGURE 12: Impact of $\beta$ on ordering quantity under demand certainty and uncertainty.

in the two channels, and thus, the newsvendor must increase ordering quantities.

As shown in Figures 13 to 17, these results are consistent with the theory analyzed in the previous section. The profit under demand certainty is never less than that under demand uncertainty. Figure 13 indicates that the profit of the newsvendor increases as $\mu$ increases. The profit benefits from demand and price increase. Figure 14 shows that the profit of the newsvendor under demand uncertainty decreases with increasing $\sigma$, whereas the profit under demand certainty remains the same. This finding is straightforward because an increase in $\sigma$ indicates an increase in risk; thus, the profits of the newsvendor under demand uncertainty decreases. 


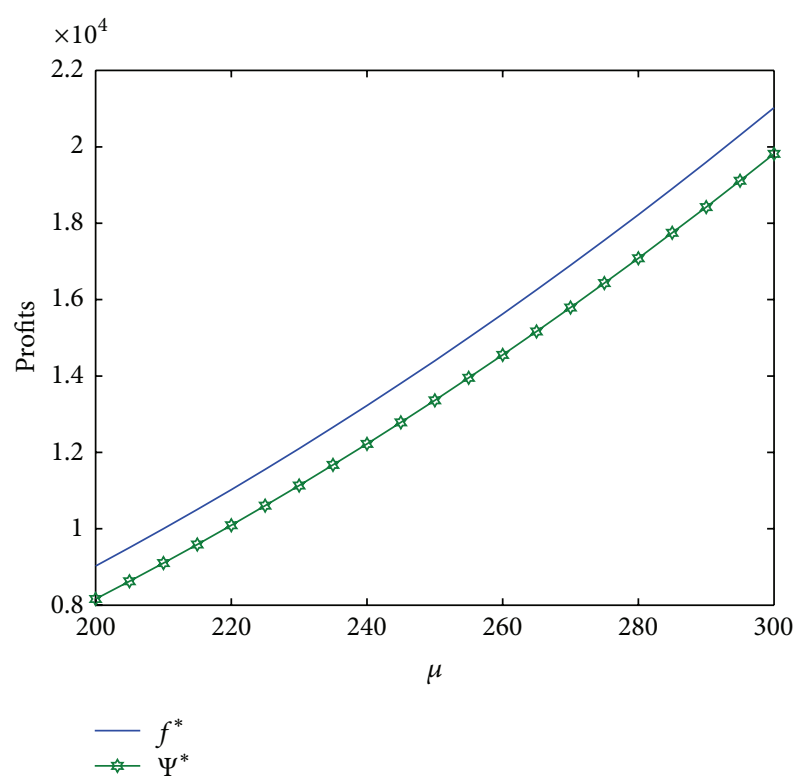

FIGURE 13: Impact of $\mu$ on the profits under demand certainty and uncertainty.

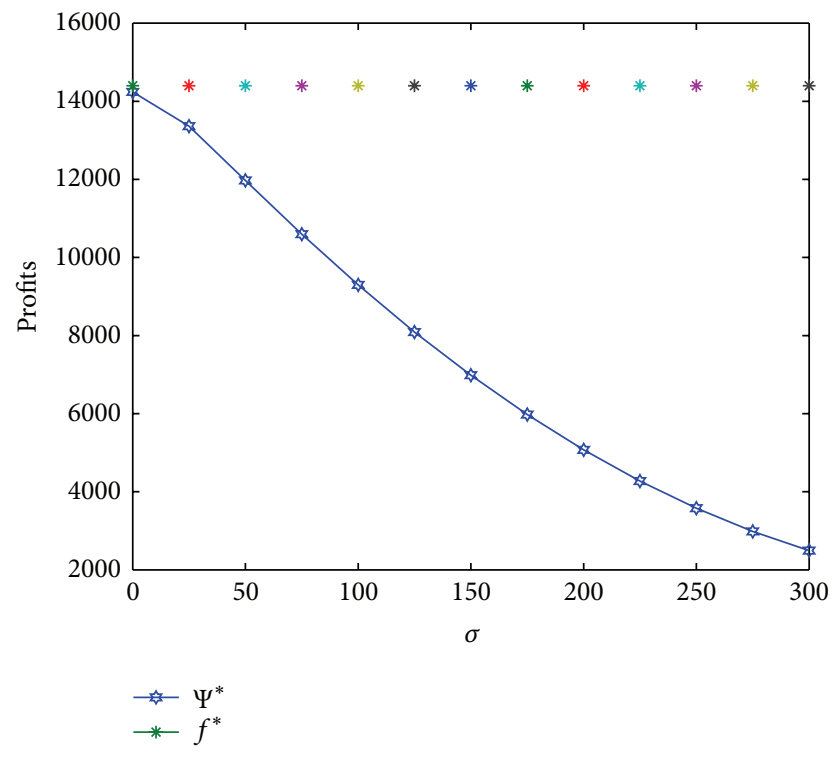

FIGURE 14: Impact of $\sigma$ on the profits under demand certainty and uncertainty.

However, no uncertainty is found under the condition of demand certainty; thus, $\sigma$ does not affect profit. Moreover, the profit under demand uncertainty decreases more slowly when $\sigma \leq 25$ than when $\sigma>25$. We also find that the effect of $\alpha_{2}$ on profit under demand uncertainty is greater when $\alpha_{1}<1, \alpha_{2}<1$. However, the effect of $\alpha_{1}$ on profit under demand uncertainty is greater when $\alpha_{1}>1, \alpha_{2}>1$. From Figure 17, we can see that profits increase as $\beta$ increases. Furthermore, when $\beta \geq 0.5$, profits increase faster.

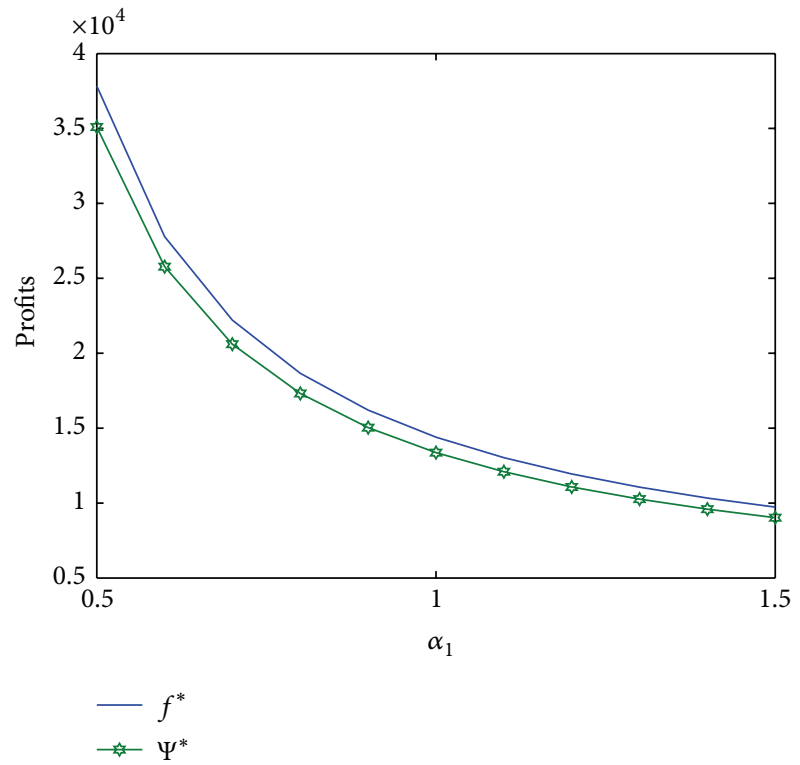

FIGURE 15: Impact of $\alpha_{1}$ on the profits under demand certainty and uncertainty.

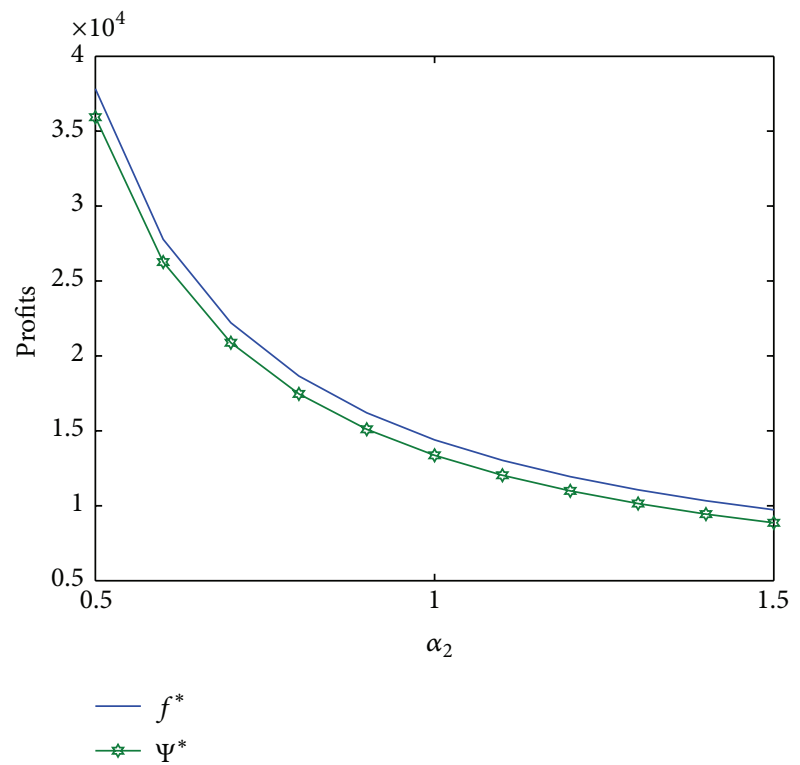

FIGURE 16: Impact of $\alpha_{2}$ on the profits under demand certainty and uncertainty.

\section{Conclusions}

In this research, we use the maximin robust approach to study the generalized newsvendor problem, in which the newsvendor sells a single product through the Internet and the traditional retail channel. Moreover, the newsvendor makes a joint decision, which includes pricing and purchasing quantity, with only partial information (mean and variance). We provided a decision-making aid to the newsvendor and analyzed the effects of some parameters or uncertainties on the pricing, purchasing quantity decisions, and profits of 


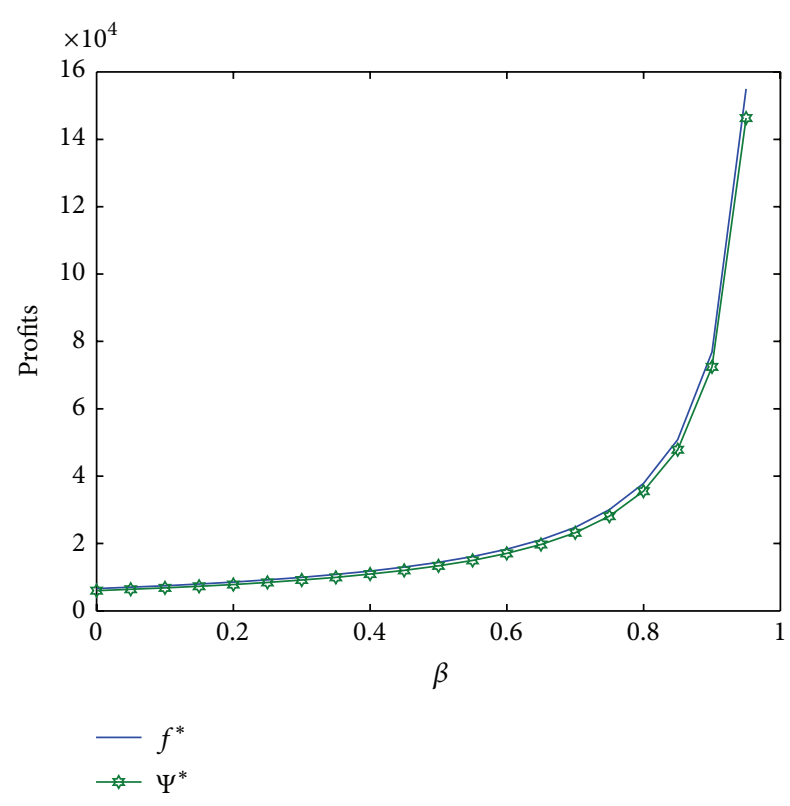

Figure 17: Impact of $\beta$ on the profits under demand certainty and uncertainty.

the newsvendor. We obtained new results that differ from those presented in literature. We found that customers will always benefit from uncertainty despite channel preference. The expected market size and the price elastic coefficient strongly influenced the pricing strategies and profits of the newsvendor. However, $\sigma$ exhibited less effect on newsvendor decisions, which indicates that our robust model has good stability. Finally, we found that our model improves performance significantly. Therefore, joint decision can be an effective approach to overcome the conservativeness of robust decisions. This implication is an interesting topic for future study.

This study has several limitations. First, it only considered one newsvendor, whereas many newsvendors are engaged in online sales and competition can significantly change pricing or purchasing strategies. Cheung and Zhuang [59] consider a similar competition as a simultaneous game within a sequential game setting. Jiang et al. [21] performs a generalized analysis of competition among newsvendors, in which competitors possess asymmetric information on future demand realizations. These cases will be interesting to study under dual or multichannel conditions. Second, a linear function was used to depict the demand faced by the newsvendor in two channels. Therefore, we will consider some other demand functions, such as the multiplicative demand model, attraction model, and Cobb-Douglas model. Finally, only one period and one purchasing chance are considered in this study. The multi-period or second order should also be investigated. Thus, we will investigate similar scenarios and simultaneously consider a second order in the future.

\section{Conflict of Interests}

The authors have declared that there is no conflict of interests.

\section{Acknowledgments}

The authors would like to thank the authors of the references for enlightening them. This paper was supported by National Natural Science Foundation of China (Grant numbers 71272085 and 71201027) and the Humanities and Social Sciences Program of the Ministry of Education of China (12YJA630135).

\section{References}

[1] M. Mangalindan, "Online retail sales are expected to rise to $\$ 172$ billion this year," The Wall Street Jouanal, 2005.

[2] G. Gallego and I. Moon, "Distribution free newsboy problem: review and extensions," Journal of the Operational Research Society, vol. 44, no. 8, pp. 825-834, 1993.

[3] H. Scarf, "A min-max solution of an inventory problem," in Studies in The Mathematical Theory of Inventory and Production, K. Arrow, S. Karlin, and H. Scarf, Eds., chapter 12, pp. 201-209, 1958.

[4] I. Moon and S. Choi, "The distribution free newsboy problem with balking," The Journal of the Operational Research Society, vol. 46, no. 4, pp. 537-542, 1995.

[5] I. Moon and S. Choi, "Distribution free procedures for maketo-order (MTO), make-in-advance (MIA), and composite policies," International Journal of Production Economics, vol. 48, no. 1, pp. 21-28, 1997.

[6] J. Mostard, R. de Koster, and R. Teunter, "The distribution-free newsboy problem with resalable returns," International Journal of Production Economics, vol. 97, no. 3, pp. 329-342, 2005.

[7] H. K. Alfares and H. H. Elmorra, "The distribution-free newsboy problem: extensions to the shortage penalty case," International Journal of Production Economics, vol. 93-94, pp. 465-477, 2005.

[8] J. Wu, J. Li, S. Y. Wang, and T. C. E. Cheng, "Mean-variance analysis of the newsvendor model with stockout cost," Omega, vol. 37, no. 3, pp. 724-730, 2009.

[9] W. Jammernegg and P. Kischka, "Risk preferences and robust inventory decisions," International Journal of Production Economics, vol. 118, no. 1, pp. 269-274, 2009.

[10] Y. Liao, A. Banerjee, and C. Yan, "A distribution-free newsvendor model with balking and lost sales penalty," International Journal of Production Economics, vol. 133, no. 1, pp. 224-227, 2011.

[11] Q. M. Han, D. L. Du, and L. F. Zuluaga, "A risk- and ambiguityaverse extension of the max-min newsvendor order formula," Operations Research, vol. 62, no. 3, pp. 535-542, 2014.

[12] G. Gallego, "A minmax distribution free procedure for the $(Q, R)$ inventory model," Operations Research Letters, vol. 11, no. 1, pp. 55-60, 1992.

[13] I. Moon and G. Gallego, "Distribution free procedures for some inventory models," Journal of the Operational Research Society, vol. 45 , no. 6, pp. 651-658, 1994.

[14] G. Gallego, "New bounds and heuristics for (Q, r) policies," Management Science, vol. 44, no. 2, pp. 219-233, 1998.

[15] A. Özler, B. Tan, and F. Karaesmen, "Multi-product newsvendor problem with value-at-risk considerations," International Journal of Production Economics, vol. 117, no. 2, pp. 244-255, 2009.

[16] L. J. Savage, "The theory of statistical decisions," Journal of the American Statistical Association, vol. 46, no. 253, pp. 55-67, 1951. 
[17] G. L. Vairaktarakis, "Robust multi-item newsboy models with a budget constraint," International Journal of Production Economics, vol. 66, no. 3, pp. 213-226, 2000.

[18] J. Yue, B. Chen, and M. Wang, "Expected value of distribution information for the newsvendor problem," Operations Research, vol. 54, no. 6, pp. 1128-1136, 2006.

[19] G. Perakis and G. Roels, "Regret in the newsvendor model with partial information," Operations Research, vol. 56, no. 1, pp. 188203, 2008.

[20] J. Lin and T. S. Ng, "Robust multi-market newsvendor models with interval demand data," European Journal of Operational Research, vol. 212, no. 2, pp. 361-373, 2011.

[21] H. Jiang, S. Netessine, and S. Savin, "Robust newsvendor competition under asymmetric information," Operations Research, vol. 59, no. 1, pp. 254-261, 2011.

[22] J. Andersson, K. Jörnsten, S. Nonås, L. Sandal, and J. Ubøe, “A maximum entropy approach to the newsvendor problem with partial information," European Journal of Operational Research, vol. 228, no. 1, pp. 190-200, 2013.

[23] T. M. Whitin, "Inventory control and price theory," Management Science, vol. 2, no. 1, pp. 61-68, 1955.

[24] N. C. Petruzzi and M. Dada, "Pricing and the newsvendor problem: a review with extensions," Operations Research, vol. 47, no. 2, pp. 183-194, 1999.

[25] M. J. Khouja, "Optimal ordering, discounting, and pricing in the single-period problem," International Journal of Production Economics, vol. 65, no. 2, pp. 201-216, 2000.

[26] N. C. Petruzzi and M. Dada, "Information and inventory recourse for a two-market, price setting retailer," Manufacturing and Service Operations Management, vol. 3, no. 3, pp. 242-263, 2001.

[27] K. Pan, K. K. Lai, L. Liang, and S. C. H. Leung, “Two-period pricing and ordering policy for the dominant retailer in a twoechelon supply chain with demand uncertainty," Omega, vol. 37, no. 4, pp. 919-929, 2009.

[28] P. C. Yang, "Pricing strategy for deteriorating items using quantity discount when demand is price sensitive," European Journal of Operational Research, vol. 157, no. 2, pp. 389-397, 2004.

[29] M. Karakul, "Joint pricing and procurement of fashion products in the existence of clearance markets," International Journal of Production Economics, vol. 114, no. 2, pp. 487-506, 2008.

[30] J. Chen and P. C. Bell, "The impact of customer returns on pricing and order decisions," European Journal of Operational Research, vol. 195, no. 1, pp. 280-295, 2009.

[31] Y. He, X. Zhao, L. Zhao, and J. He, "Coordinating a supply chain with effort and price dependent stochastic demand," Applied Mathematical Modelling, vol. 33, no. 6, pp. 2777-2790, 2009.

[32] Y. Chen, M. Xu, and Z. G. Zhang, "A risk-averse newsvendor model under the CVaR criterion," Operations Research, vol. 57, no. 4, pp. 1040-1044, 2009.

[33] W. Xing, S. Y. Wang, and L. M. Liu, "Optimal ordering and pricing strategies in the presence of a B2B Spot market," European Journal of Operational Research, vol. 221, no. 1, pp. 8798, 2012.

[34] G. W. Hua, S. Y. Wang, and T. C. E. Cheng, "Optimal pricing and order quantity for the newsvendor problem with free shipping," International Journal of Production Economics, vol. 135, no. 1, pp. 162-169, 2012.

[35] D. A. Serel, "Optimal ordering and pricing in a quick response system," International Journal of Production Economics, vol. 121, no. 2, pp. 700-714, 2009.
[36] Y. Li, C. Wei, and X. Cai, "Optimal pricing and order policies with $\mathrm{B} 2 \mathrm{~B}$ product returns for fashion products," International Journal of Production Economics, vol. 135, no. 2, pp. 637-646, 2012.

[37] S. Balasubramanian, "Mail versus mall: a strategic analysis of competition between direct marketers and conventional retailers," Marketing Science, vol. 17, no. 3, pp. 181-195, 1998.

[38] R. Levary and R. G. Mathieu, "Hybrid retail : integrating ecommerce and physical stores," Industrial Management, vol. 42, no. 5, pp. 6-13, 2000.

[39] W. K. Chiang, D. Chhajed, and J. D. Hess, "Direct marketing, indirect profits: a strategic analysis of dual-channel supplychain design," Management Science, vol. 49, no. 1, pp. 1-20, 2003.

[40] D. Yao and J. J. Liu, "Channel redistribution with direct selling," European Journal of Operational Research, vol. 144, no. 3, pp. 646-658, 2003.

[41] G. E. Fruchter and C. S. Tapiero, "Dynamic online and offline channel pricing for heterogeneous customers in virtual acceptance," International Game Theory Review, vol. 7, no. 2, pp. 137150, 2005.

[42] G. G. Cai, Z. G. Zhang, and M. Zhang, "Game theoretical perspectives on dual-channel supply chain competition with price discounts and pricing schemes," International Journal of Production Economics, vol. 117, no. 1, pp. 80-96, 2009.

[43] H. Xu, Z. Z. Liu, and S. H. Zhang, "A strategic analysis of dualchannel supply chain design with price and delivery lead time considerations," International Journal of Production Economics, vol. 139, no. 2, pp. 654-663, 2012.

[44] G. W. Hua, S. Y. Wang, and T. C. E. Cheng, "Price and lead time decisions in dual-channel supply chains," European Journal of Operational Research, vol. 205, no. 1, pp. 113-126, 2010.

[45] B. Dan, G. Y. Xu, and C. Liu, "Pricing policies in a dualchannel supply chain with retail services," International Journal of Production Economics, vol. 139, no. 1, pp. 312-320, 2012.

[46] J. Chen and P. C. Bell, "Implementing market segmentation using full-refund and no-refund customer returns policies in a dual-channel supply chain structure," International Journal of Production Economics, vol. 136, no. 1, pp. 56-66, 2012.

[47] D. Yao, X. Yue, X. Wang, and J. J. Liu, "The impact of information sharing on a returns policy with the addition of a direct channel," International Journal of Production Economics, vol. 97, no. 2, pp. 196-209, 2005.

[48] X. Yue and J. Liu, "Demand forecast sharing in a dual-channel supply chain," European Journal of Operational Research, vol. 174, no. 1, pp. 646-667, 2006.

[49] R. L. Yan and S. Ghose, "Forecast information and traditional retailer performance in a dual-channel competitive market," Journal of Business Research, vol. 63, no. 1, pp. 77-83, 2010.

[50] R. Yan and Z. Pei, "Information asymmetry, pricing strategy and firm's performance in the retailer- multi-channel manufacturer supply chain," Journal of Business Research, vol. 64, no. 4, pp. 377-384, 2011.

[51] S. Huang, C. Yang, and X. Zhang, "Pricing and production decisions in dual-channel supply chains with demand disruptions," Computers and Industrial Engineering, vol. 62, no. 1, pp. 70-83, 2012.

[52] S. C. Choi, "Price competition in a duopoly common retailer channel," Journal of Retailing, vol. 72, no. 2, pp. 117-134, 1996.

[53] J. S. Raju and A. Roy, "Market information and firm performance," Management Science, vol. 46, no. 8, pp. 1075-1084, 2000 . 
[54] W. Huang and J. M. Swaminathan, "Introduction of a second channel: implications for pricing and profits," European Journal of Operational Research, vol. 194, no. 2, pp. 258-279, 2009.

[55] J. Huang, M. Leng, and M. Parlar, "Demand functions in decision modeling: a comprehensive survey and research directions," Decision Sciences, vol. 44, no. 3, pp. 557-609, 2013.

[56] E. S. Mills, "Uncertainty and price theory," The Quarterly Journal of Economics, vol. 73, no. 1, pp. 116-130, 1959.

[57] E. A. Silver and R. Perterson, Decision Systems for Inventory Management and Production Planning, John Wiley \& Sons, New York, NY, USA, 1985.

[58] E. Zabel, "Monopoly and uncertainty," The Review of Economic Studies, vol. 37, no. 2, pp. 205-219, 1970.

[59] M. Cheung and J. Zhuang, "Regulation games between government and competing companies: oil spills and other disasters," Decision Analysis, vol. 9, no. 2, pp. 156-164, 2012. 


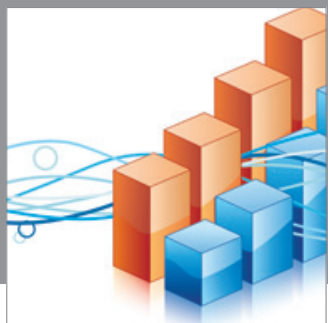

Advances in

Operations Research

mansans

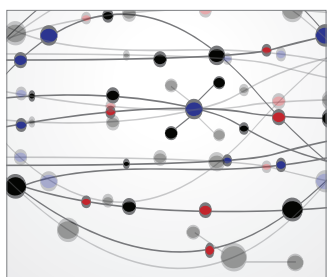

The Scientific World Journal
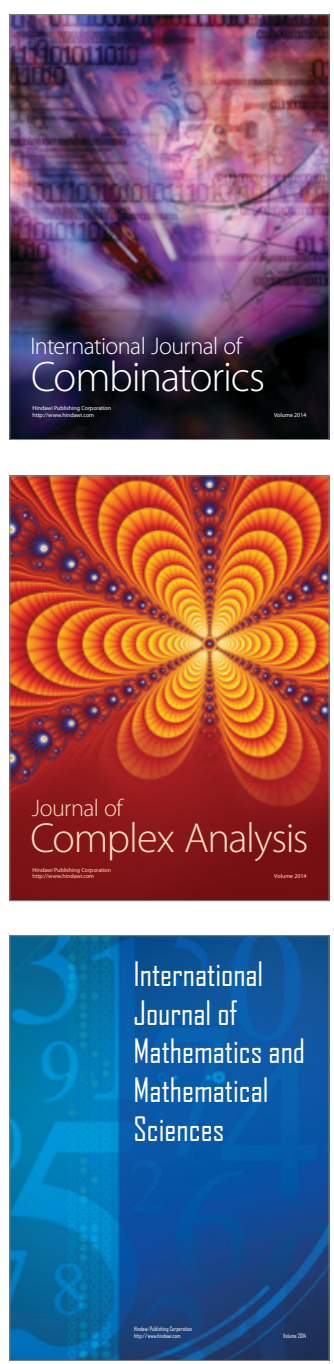
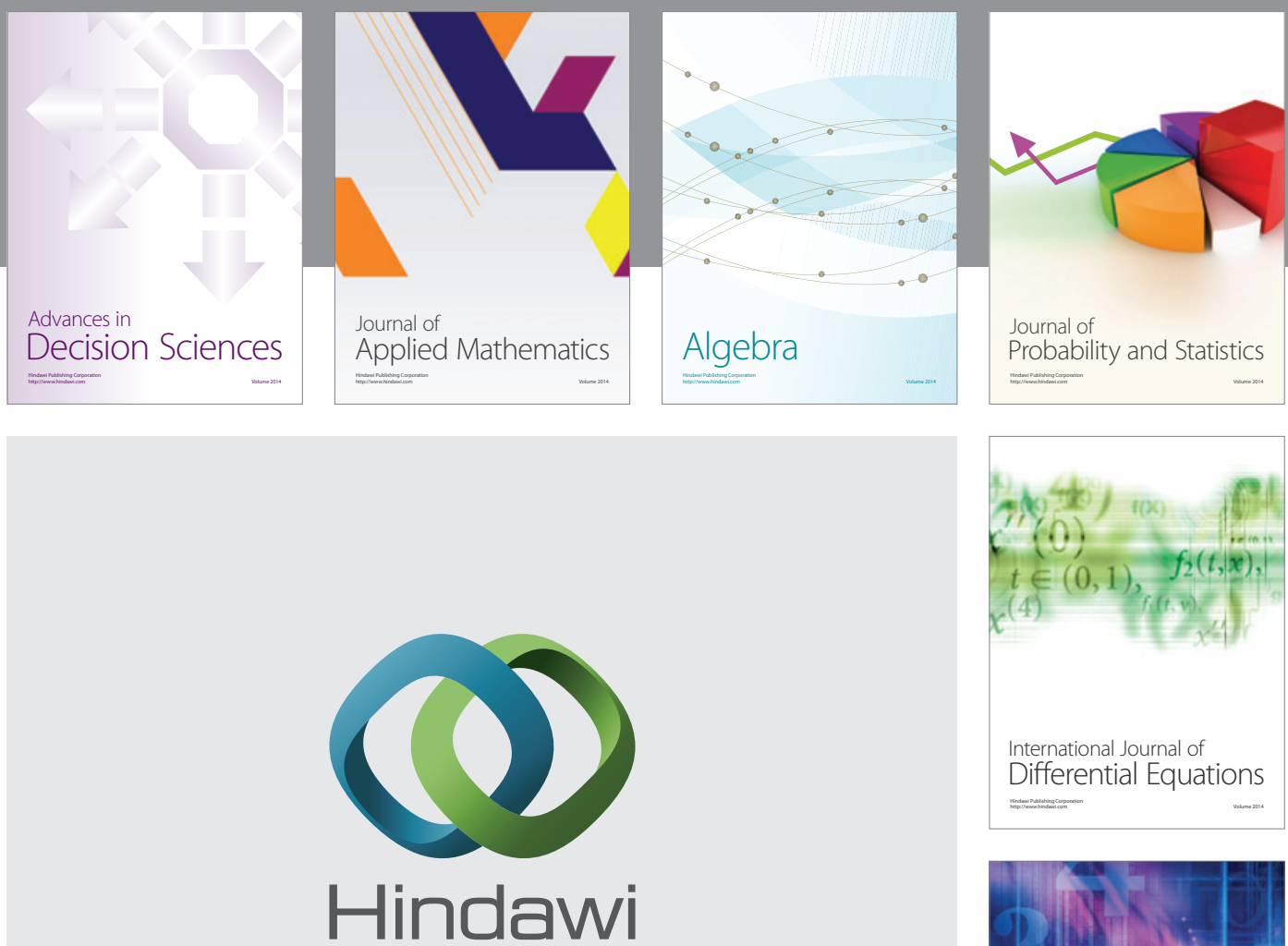

Submit your manuscripts at http://www.hindawi.com
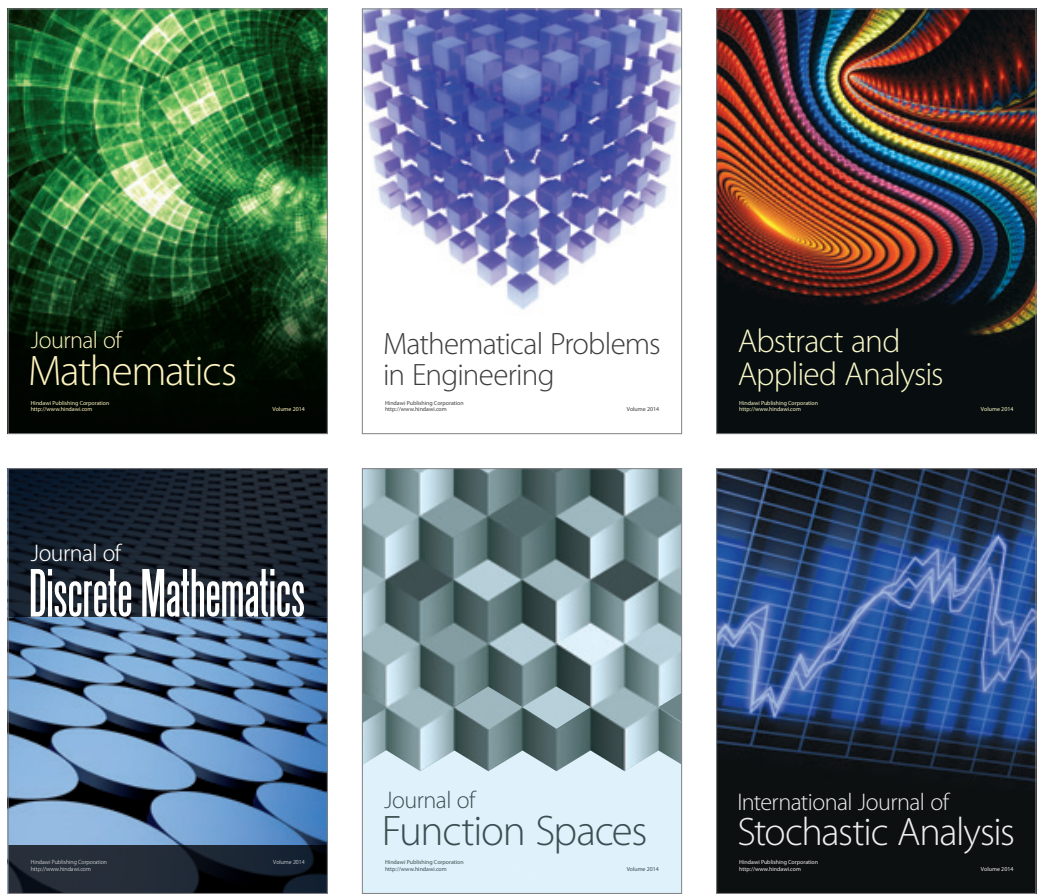

Journal of

Function Spaces

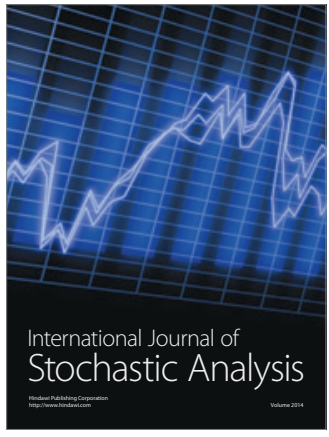

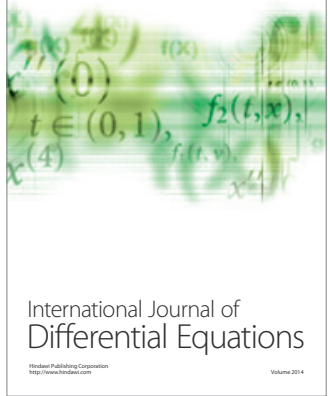
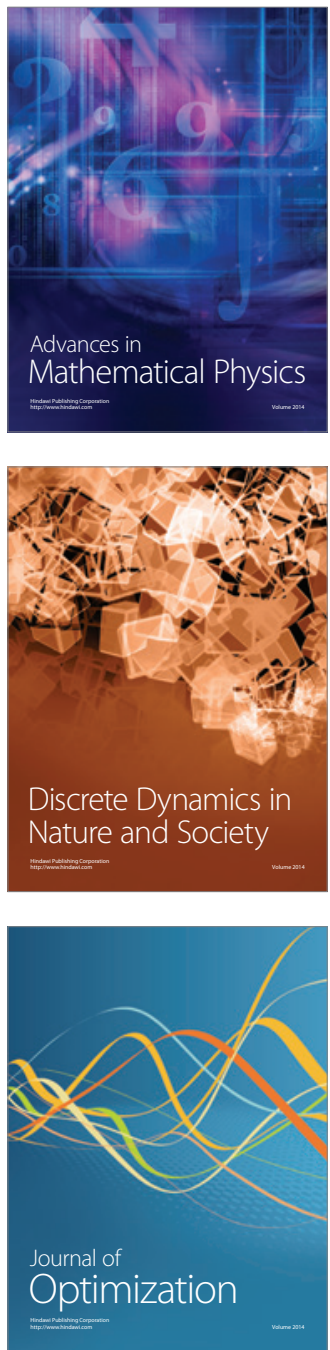